\title{
Substituting meat/fish for mycoprotein for one week does not affect indices of metabolic health irrespective of dietary nucleotide load or serum uric acid concentrations in healthy young adults
}

\author{
M. Coelho ${ }^{1}$, A.J. Monteyne ${ }^{1}$, M.L. Dirks ${ }^{1}$, T.J.A. Finnigan ${ }^{2}$, F.B. Stephens ${ }^{1}$ and B.T. Wall ${ }^{1}$ \\ ${ }^{1}$ Department of Sport and Health Sciences, University of Exeter, Exeter EXI $2 L U$ and ${ }^{2}$ Marlow Foods Ltd, \\ Stokesley TS9 $7 A B$.
}

Mycoprotein is a sustainably-produced, fungal-derived dietary protein source and its acute ingestion has positive effects on postprandial glycaemic control and blood lipid profiles ${ }^{(1)}$. However, the impact of incorporating mycoprotein into a habitual diet on markers of metabolic health has not been assessed. Nucleotide content of mycoprotein is reduced during production (to levels similar to meat) due to concerns over acute dietary nucleotide intake elevating circulating uric acid concentrations, and reported negative associations between serum uric acid concentrations and metabolic health ${ }^{(2,3)}$. However, intervention studies examining the impact of dietary nucleotide load upon metabolic health are not available. Our objective was to assess the impact of substituting meat/fish for mycoprotein, containing either a high or low nucleotide content, during a one week intervention period, on insulin sensitivity, glycaemic control and serum uric acid concentrations in healthy adults.

Thirty healthy (BMI: $\left.24 \pm 3 \mathrm{~kg} / \mathrm{m}^{2}\right)$ young $(24 \pm 4 \mathrm{y})$ adults $(m=12, f=8)$ participated in a randomised, parallel group trial in which they consumed a $7 \mathrm{~d}$ fully controlled, energy-balanced (using IPAQ data and the Henry equation) diet where lunch and dinner contained either meat/fish (CON; $n=10)$, nucleotide-depleted mycoprotein (LN-MYC; $n=10)$ or nucleotide-rich mycoprotein (HN-MYC) as the major source of dietary protein. Mycoprotein was provided as Quorn Foods ${ }^{\mathrm{TM}}$ products. The allotted protein source provided approx. $40-50 \%$ of the total daily protein intake (with a total daily intake of $1.2 \mathrm{~g}$ per $\mathrm{kg}$ bm). An oral glucose tolerance test (OGTT) was performed pre- and post- dietary intervention to measure insulin sensitivity, and continuous glucose monitoring was applied throughout the intervention to assess $24 \mathrm{~h}$ glycaemic control. Fasting blood and urine samples were taken throughout the intervention to measure uric acid concentrations.

Insulin sensitivity (expressed as Cederholm SI) calculated during the OGTT was not different between groups at baseline (51 \pm 11 , $54 \pm 10$ and $58 \pm 10 \mathrm{mg} .1^{2} / \mathrm{mmol} . \mathrm{mU} . \mathrm{min}$ in CON, LN-MYC and HN-MYC, respectively) and was not affected by the intervention $\left(51 \pm 9,55 \pm 9\right.$ and $54 \pm 10 \mathrm{mg} .1^{2} / \mathrm{mmol} . \mathrm{mU}$.min, respectively). Average $24 \mathrm{~h}$ glycaemic profiles during the intervention were equivalent across groups. Serum uric acid concentrations were equivalent at baseline across groups $(P>0 \cdot 05)$ and remained constant in the CON $\left(\sim 296 \mu \mathrm{mol} . \mathrm{L}^{-1}\right)$ and LN-MYC $\left(\sim 282 \mu \mathrm{mol} . \mathrm{L}^{-1}\right)$ groups. In HN-MYC, serum uric acid concentrations steadily increased from baseline $\left(295 \pm 55 \mu \mathrm{mol} . \mathrm{L}^{-1}\right)$ at $2\left(402 \pm 59 \mu \mathrm{mol} . \mathrm{L}^{-1} ; P<0.05\right), 4\left(455 \pm 78 \mu \mathrm{mol} . \mathrm{L}^{-1} ; P<0.05\right)$ and $6\left(472 \pm 93 \mu \mathrm{mol} . \mathrm{L}^{-1} ; P<0.05\right)$ days before decreasing (but remaining elevated compared with baseline; $P<0.05)$ on day $8\left(409 \pm 73 \mu \mathrm{mol} . \mathrm{L}^{-1} ; P<0 \cdot 05\right)$. Baseline urine uric acid concentrations were the same across groups and were not affected by the intervention.

To conclude, substituting meat/fish for mycoprotein at lunch and dinner for one week has no impact on markers of metabolic health in healthy young adults. Furthermore, if the mycoprotein consumed is high in dietary nucleotides a sustained elevation in serum uric acid concentrations occurs; however, this does not affect insulin sensitivity or glycaemic control. Mycoprotein, irrespective of nucleotide content, can be incorporated into the diet as a sustainable alternative protein source without compromising metabolic health.

This project was sponsored by Marlow Foods Ltd.

1. Denny A, Aisbitt B \& Lunn J (2008 Dec 1) Nutr Bull 33(4), 298-310.

2. British Nutrition Foundation (2016) Report.

3. Kanbay M, Jensen T, Solak Y et al. (2016 Apr 1) Eur. J. Intern. Med 29, 3-8. 